\title{
How much of a primary care nurse's time is spent on those with respiratory disease? A pilot study
}

\section{Daniel Blake ${ }^{a}$, Nicola J Roberts ${ }^{b}, *$ Martyn R Partridge ${ }^{c}$}

\footnotetext{
a Medical Student, Imperial College London, Charing Cross Hospital Campus, London, UK

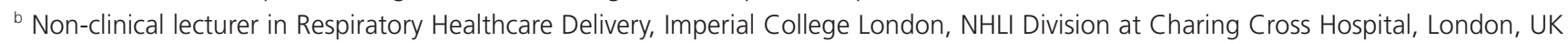

c Professor of Respiratory Medicine, Imperial College London, NHLI Division at Charing Cross Hospital, St Dunstan's Road, London, W6 8RP, UK
}

Received 7th January 2007; accepted 26th March 2007

\begin{abstract}
Summary
A pilot study was undertaken to assess the respiratory component of primary care nurses' working time. 13 nurses were interviewed and 10 completed a diary during one working week. The nurses spent a mean $6.6 \%$ of their time caring for those with respiratory disease and were of the opinion that during this time they undertook $68 \%$ of the management of long term respiratory illness in the practices. More time was spent with those with asthma than with other respiratory conditions and the nurses felt that they were appropriately trained for the tasks undertaken. However, with more training they felt that they could undertake more basic care of those patients with COPD, and more advanced care of those patients with asthma.
\end{abstract}

(C) 2007 General Practice Airways Group. All rights reserved.

D Blake, et al. Prim Care Resp J 2007; 16(5): 319-320.

doi:10.3132/pcrj.2007.00061

Keyw ords training, chronic disease management, practice nurse

\section{Introduction}

There is a high burden of respiratory disease in primary care some acute and probably self-limiting, and some involving supervision and support of those with long-term disorders such as asthma and chronic obstructive pulmonary disease (COPD). Shum et al. have shown in a randomised controlled trial that patients are more satisfied with primary care nurse practitioner consultations compared with general practitioner (GP) consultations: ${ }^{1}$ during nurse consultations patients were given significantly more advice about selfmedication and general self-management advice. A recent Cochrane review into the effect of substitution of doctors by nurses in primary care found supporting evidence for this, despite a limited number of studies and limited potential for data synthesis. ${ }^{2}$ One study found that in six areas across the UK - representing a mixed socio-economic background there was a rise in the number of practice nurses employed in group general practices from $60 \%$ to $96 \%$ between 1987 and $1993 .{ }^{3}$ Nurses are known to play an active role in asthma care. $^{4}$
Therefore, in this pilot study, we investigated the current role of nurses delivering respiratory care in London general practices, and studied the amount of time they spent on this purpose as well as their views regarding their training and roles.

\section{Methods}

A one-to-one interview with 13 nurses from eight general practices in South and West London was carried out to identify practice and nurse characteristics, their views about their current involvement in respiratory care, and the potential for improvement. The nurses were then given a tick box diary to record the consultations they undertook over a subsequent one-week period.

\section{Results}

A total of 13 nurses were interviewed, and 10 of these nurses (working in seven different health centres in London) fully completed the diaries. On average, the nurses worked 35 hours per week, and had a mean of over 16 years of nursing

* Corresponding author: Tel: +44 (0)20 88467181 Fax: +44 (0)20 88467999 E-mail: m.partridge@imperial.ac.uk 
experience. All practices had in-house spirometry; five nurses performed spirometry and two out of 13 reported that they interpreted the results. From the diaries, nurses reported spending a mean of $6.6 \%$ of total nurse consultation time with patients with respiratory disease, and $4.2 \%$ of all working time on this task. The most common reason for a nurse consultation was for travel advice or vaccinations, which accounted for $15.5 \%$ of all consultations. Other major responsibilities concerned follow-up of those with hypertension and risk of vascular disease (13.6\%), and women's and men's health (12.4\%). Fifty-nine percent of the respiratory consultations concerned asthma, 34\% COPD, and $7 \%$ other respiratory diseases. No significant association was found between the practice and nurse characteristics (e.g. formal training) and the amount of time spent on respiratory medicine. Nurses identified advanced asthma care (e.g. the giving of asthma action plans) and basic COPD as areas where they felt they could deliver more, given more training. The majority of nurses were happy that they had sufficient training to deliver the respiratory care they currently delivered. When asked, nurses estimated that $68 \%$ of the long term respiratory illness management in their practices was given by nurses.

\section{Discussion}

Although nurses spent only a small amount of their time on respiratory medicine, this was sufficient to manage the regular review of the majority of patients with asthma and COPD within a given practice. This probably reflects their main role in managing respiratory disease in primary care. The reason the amount of nurse time spent on respiratory illness is low when respiratory illness is the commonest reason for consultation in primary care ${ }^{5}$ is probably because GPs are seeing those with acute respiratory illness whilst nurses are concentrating on the regular review of those with long-term respiratory conditions.

This was only a small UK pilot study of nurses working in South and West London and it needs to be replicated elsewhere. Nevertheless, it appears that the respiratory care offered by nurses in primary care is almost exclusively in chronic disease management and that this represents only a small part of their working day. The nurses interviewed in this study expressed a desire to undertake more advanced care of patients with both asthma and COPD, but their impact on the respiratory workload overall within a practice is only likely to become significant if they see more patients with acute respiratory illnesses as well.

\section{Conflicts of interest declaration}

There are no conflicts of interest to declare.

\section{Acknow ledgements}

Rosie Price (Practice Nurse Development Officer), Professor Rifat Atun of The Tanaka Business School, and Dr Jeremy Grey (GP, Lavender Hill Group Practice) all gave helpful advice in the undertaking of this study. We thank them and all the nurses involved in the study for their co-operation.

\section{References}

1. Shum C, Humphreys A, Wheeler D, Cochrane MA, Skoda S, Clement S. Nurse management of patients with minor illnesses in general practice: multicentre, randomised controlled trial. BMJ 2000;320(7241):1038-43.

2. Laurant M, Reeves D, Hermens R, Braspenning J, Grol R, Sibbald B. Substitution of doctors by nurses in primary care. Cochrane Database Syst Rev 2005; (2):CD001271.

3. Leese $B$, Bosanquet $N$. Change in general practice and its effects on service provision in areas with different socioeconomic characteristics. BMJ 1995; 311(7004):546-50.

4. Barnes G, Partridge MR. Community asthma clinics: 1993 survey of primary care by the National Asthma Task Force. Qual Health Care 1994;3(3):133-6.

5. British Thoracic Society. The burden of lung disease. A statistical report from the British Thoracic Society. British Thoracic Society 2000.

\section{Available online at http://ww w.thepcrj.org}

